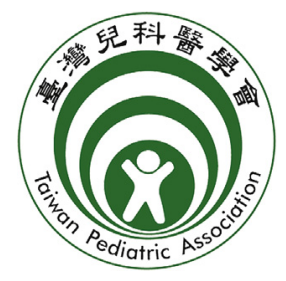

\title{
Myocardial Injury Biomarkers in Newborns with Congenital Heart Disease
}

\author{
Ana Luisa Neves a,b,c,*, Maria Cabral d , Adelino Leite-Moreira b,e, \\ José Monterroso ${ }^{a}$, Carla Ramalho b,f,g, Hercília Guimarães ${ }^{b, h}$, \\ Henrique Barros ${ }^{b, d}$, João T. Guimarães ${ }^{b, d, i}$, \\ Tiago Henriques-Coelho ${ }^{c, j}$, José C. Areias a,b,c
}

\author{
a Department of Paediatric Cardiology, São João Hospital, Porto, Portugal \\ b Department of Physiology and Cardiothoracic Surgery, Cardiovascular Research Centre, Faculty of \\ Medicine, University of Porto, Porto, Portugal \\ c Department of Paediatrics, Faculty of Medicine, University of Porto, Porto, Portugal \\ ${ }^{d}$ EPI Unit-Institute of Public Health, University of Porto, Porto, Portugal \\ e Department of Cardiothoracic Surgery, São João Hospital, Porto, Portugal \\ ${ }^{f}$ Department of Obstetrics, São João Hospital, Porto, Portugal \\ ${ }^{g}$ Instituto de Investigação e Inovação em Saúde, Porto, Portugal \\ h Department of Neonatology, São João Hospital, Porto, Portugal \\ ' Department of Clinical Pathology, São João Hospital, Porto, Portugal \\ j Department of Paediatric Surgery, São João Hospital, Porto, Portugal
}

Received Mar 31, 2015; received in revised form Oct 22, 2015; accepted Nov 10, 2015 Available online 2 April 2016

\author{
Key Words \\ cardiac biomarkers; \\ congenital heart \\ disease; \\ echocardiography; \\ outcome
}

\begin{abstract}
Background: Troponin I, myoglobin, and creatine kinase-MB mass (CK-MB) are biomarkers of cardiomyocyte injury widely used in the management of adult patients. The role of these biomarkers in newborns is still not established. The purpose of this study was to evaluate the value of cardiac injury biomarkers in newborns with congenital heart disease.

Methods: From August 2012 to January 2014, 34 newborns with a prenatal diagnosis of congenital heart disease were admitted consecutively to a neonatal intensive care unit. As controls, 20 healthy newborns were recruited. Plasma levels of cardiac biomarkers (troponin I, myoglobin, and $(\mathrm{CK}-\mathrm{MB}$ ) were evaluated, and echocardiography was performed to evaluate cardiac function on D 1. Patients were followed during the first 28 days of life and, according to outcome, categorized as surgical or conservative treatment group.

Results: Median (P25-75) levels of CK-MB were higher in patients who underwent cardiac surgery in the neonatal period $[7.35(4.90-13.40) \mathrm{ng} / \mathrm{mL}]$ than in patients who were discharged home without surgery $[4.2(2.60-5.90) \mathrm{ng} / \mathrm{mL} ; p=0.032]$. A CK-MB cutoff of $\geq 4.6 \mathrm{ng} / \mathrm{mL}$
\end{abstract}

\footnotetext{
* Corresponding author. Department of Paediatric Cardiology, Hospital São João, Alameda Professor Hernâni Monteiro, 4200-319 Porto, Portugal.

E-mail address: alneves1@gmail.com (A.L. Neves).
} 
showed sensitivity of $87.5 \%$ and specificity of $63.6 \%$. Troponin I and myoglobin levels were not significantly different between conservative and surgical treatment groups. CK-MB levels correlated with the tissue Doppler image of the mitral valve lateral annulus peak early/late diastolic velocity ratio $(\rho=-0.480, p=0.018)$.

Conclusion: CK-MB levels during the first hours of life were higher in newborns that needed neonatal cardiac surgery, and these levels may be an indicator of myocardial diastolic function.

Copyright @ $\odot$ 2016, Taiwan Pediatric Association. Published by Elsevier Taiwan LLC. This is an open access article under the CC BY-NC-ND license (http: //creativecommons.org/licenses/ by-nc-nd/4.0/).

\section{Introduction}

Creatine kinase-MB mass (CK-MB), myoglobin, and cardiac troponins I and $\mathrm{T}$ are cardiac injury biomarkers widely used in the management of adult patients. ${ }^{1,2}$ Interest in these cardiac biomarkers in the management of children with congenital heart disease (CHD) has increased; however, there are no current guidelines for their routine use. Reference values for CK-MB and cardiac troponins $\mathrm{T}$ and I in healthy neonates have been published. ${ }^{3-6}$ CK-MB levels were elevated in newborns after perinatal and neonatal hypoxia-ischemia, but this elevation was not specific enough to be of clinical value. ${ }^{7}$ Myoglobin is a cytoplasmic protein in cardiac and skeletal muscle, and it passes rapidly into circulation after damage to the myocytes. ${ }^{6,8}$ Troponin I was found to be a very sensitive and specific marker of cardiac injury. 2,4,9 Troponin I has been used to detect myocardial compromise in newborns with hypoxia and asphyxia, ${ }^{10,11}$ and it was shown to be useful for monitoring myocardial injury in infants of diabetic mothers: an elevated troponin I in infants of diabetic mothers with respiratory distress was a good predictor of hypertrophic cardiomyopathy and/or left ventricular dysfunction. ${ }^{12}$ Troponin I has also been studied in children with left-toright shunt-induced myocardial injury. ${ }^{13,14}$ Further research is necessary before cardiac injury biomarkers can be used in clinical practice in this age group. ${ }^{15,16}$

Our hypothesis was that plasma cardiac injury biomarkers might be increased in newborns with $\mathrm{CHD}$, correlated with echocardiographic markers of biventricular function, and useful in the management of these patients.

\section{Methods}

\subsection{Study design and patient population}

This is a prospective study of 34 consecutive newborns with a prenatal diagnosis of $\mathrm{CHD}$, who were admitted at the Neonatal Intensive Care Unit of S. João Hospital Center, Porto, Portugal, between August 2012 and January 2014. Additionally, 20 healthy newborns delivered in the same hospital were recruited as controls. Plasma biomarkers were evaluated on Day 1 (with umbilical cord blood after birth or the first sample collected for clinical purposes). The umbilical cord blood was collected after birth following the standard protocol. In the few cases in which it was not possible to collect a cord sample (spasm of the cord or sample coagulation), the peripheral venous blood was collected as soon as a clinical sample for the newborn was performed (the first few hours of life).

Plasma biomarkers evaluated were troponin I, myoglobin, and CK-MB. In all control group newborns except for one, all the biomarkers were measured. In the CHD group, troponin I was available in 33 , myoglobin in 26 , and $C K-M B$ in 26 . The missing values were due to insufficient sample volume.

Plasma biomarkers were compared using all patients' samples and also using only cord blood samples. Troponin I, myoglobin, and CK-MB were measured by way of chemiluminescent immunoassays using an Architect i2000 automated analyzer (Abbott, Lisboa, Portugal).

CHD cases were subdivided into right ventricle pressure overload $(n=6)$, left ventricle pressure overload $(n=5)$, Ebstein disease $(n=2)$, transposition of great arteries $(n=4)$, left-to-right shunts $(n=6)$, and total pulmonary anomalous venous return $(n=1)$ groups.

The right ventricle pressure overload group included four patients with tetralogy of Fallot, one patient with double outlet right ventricle with pulmonary stenosis, and one patient with pulmonary atresia with ventricular septal defect. The left ventricle pressure overload group included two patients with coarctation of the aorta, one patient with aortic stenosis, one patient with aortic atresia with ventricular septal defect, and one patient with interruption of the aortic arch. The group of transposition of great arteries included two patients with transposition of great arteries and two patients with transposition of great arteries with ventricular septal defects. The left-to-right shunt group included three patients with atrioventricular septal defects, two patients with ventricular septal defects, and one patient with patent ductus arteriosus (PDA). Two patients were excluded because they did not have a surgical indication (supraventricular tachycardia and a small muscular ventricular septal defect).

Patients were followed during the first 28 days of life (neonatal period) and, according to the outcome, categorized as surgical or conservative treatment group.

Of the 24 patients with CHD with a surgical indication (with a type of CHD expected to require surgery at some point in life), 10 had cardiac surgery in the neonatal period: systemic to pulmonary shunts $(n=3)$, arterial switch $(n=2)$, Norwood $(n=1)$, aortic valvuloplasty $(n=1)$, pulmonary banding $(n=1)$, correction of coarctation of 
aorta $(n=1)$, and correction of interruption of aortic arch $(n=1)$. The group of transposition of great arteries included both transposition of great arteries with and that without ventricular septal defect. The patient with transposition of great arteries had two large ventricular septal defects, and it was not possible to perform the arterial switch at birth. The total anomalous pulmonary venous return was corrected after the $1^{\text {st }}$ month of postnatal life; therefore, it was not included in the neonatal surgical group (defined as surgery in the first 28 days of life).

\subsection{Echocardiographic imaging}

Echocardiography was performed on Day 1, using the General Electric Vivid I. Right ventricular, left ventricular function M-mode, and Doppler and tissue Doppler image (TDI) parameters were evaluated using standard techniques. ${ }^{17-20}$ For left ventricle systolic function, the evaluated parameters were left ventricle ejection fraction and mitral valve lateral annulus TDI slope. For right ventricle systolic function, the parameters were tricuspid annular plane systolic excursion and tricuspid valve lateral annulus TDI slope. The mitral TDI $E^{\prime} / A^{\prime}$ was acquired in the lateral side of the mitral valve annulus. Each of TDI early diastolic $\left(E^{\prime}\right)$ and late diastolic $\left(A^{\prime}\right)$ myocardial velocities was measured at the upper lateral annulus of the mitral valve during periods of stable heart rate and stable TDI waveforms. ${ }^{21}$ The apical four-chamber view was used; care was taken to align the sample volume as vertically as possible with respect to the cardiac apex, ${ }^{20}$ and the ratio $E^{\prime} / A^{\prime}$ was calculated. ${ }^{22}$ Cardiac performance evaluation was blinded for blood test results.

\subsection{Statistical analysis}

Continuous variables were presented as medians $\left(25^{\text {th }}-75^{\text {th }}\right.$ percentile) and compared using the Mann-Whitney $U$ test. Proportions were compared through the Chi-square test or Fisher exact test, as appropriate. Receiver operator characteristic curves were used to evaluate troponin I, myoglobin, and CK-MB as potential biomarkers. Assays were deemed to be potentially useful if they carried a c-statistic of $\geq 0.75$ (corresponding to $\geq 75 \%$ of the graph area encompassed by the curve). For a potentially useful test, a clinically relevant cutoff was identified that would distinguish newborns submitted to surgery from those receiving conservative treatment. ${ }^{23}$ Logistic regression models were fitted to estimate the association between biomarker levels and cardiac surgery. The association between biomarkers and echocardiographic parameters was analyzed by
Spearman's rank correlation test. SPSS version 21 (IBM, Armonk, NY, USA) was used for statistical analysis. A $p$ value $<0.05$ was considered statistically significant.

This study was approved by the São João Hospital, Porto, Portugal, Ethics Committee, and parents of all participants provided written informed consent. The newborns' physicians were blinded to the results of the biomarkers. Echocardiography was performed and analyzed blinded for biomarker results and outcome.

\section{Results}

The CHD and control groups were similar regarding gestational age [38 (37-39) weeks in CHD vs. 39 (37-40) weeks in controls, $p=0.221$ ], type of delivery (eutocic vs. dystocic, $p=0.965)$, and birth weight [CHD 3092.5 (2891.2-3446.2) $\mathrm{g}$ and control 3157.5 (2771.2-3515.0) g, $p=0.727]$.

Cardiac biomarkers were not different between eutocic and dystocic deliveries (CK-MB, $p=0.935$; troponin, $p=0.884$; myoglobin, $p=0.967)$. Levels of cardiac biomarkers were not related to patients' saturation of oxygen (CK-MB: $\beta=0.002, p=0.990$; troponin: $\beta=0.001$, $p=0.491$; myoglobin: $\beta=2.79, p=0.374$ ) or to Apgar score at Minute 1 (CK-MB: $\beta=0.794, p=0.590$; troponin: $\beta=0.005, p=0.418$; myoglobin: $\beta=19.20, p=0.451$ ) and Minute 5 (CK-MB: $\beta=2.00, p=0.300$; troponin: $\beta=0.01, p=0.428$; myoglobin: $\beta=32.60, p=0.333$ ). CK-MB and myoglobin were statistically significantly different according to blood source. For CK-MB, cord blood median was $4.2(2.8-6.6)$ and peripheral venous blood median 12.1 (5.3-21.6), $p=0.009$; for myoglobin, cord blood median was $47.20(33.0-59.0)$ and peripheral venous blood median $114.8(66.5-240.6), p=0.002$. No differences were observed regarding troponin [cord blood 0.01 (0.01-0.01), peripheral venous blood 0.01 (0.01-0.04), $p=0.189]$. Using only the cord blood samples, higher levels of CK-MB were observed in those who needed neonatal surgery compared with the newborns that were discharged home without surgery $(7.30$ vs. 3.65 , $p=0.091)$. In regard to the peripheral blood, the sample was small $(n=6)$, which did not allow us to compare these groups.

Troponin I, myoglobin, and CK-MB levels were not significantly different between the control and CHD groups (Table 1) or between groups of CHD (Table 2).

Surgical and conservative treatment groups were similar regarding gestational age, type of birth, and birth weight, and they had a similar Apgar score at 1 minute and $5 \mathrm{mi}-$ nutes (Table 3). Median (P25-75) levels of CK-MB were higher in patients who had cardiac surgery in the neonatal

Table 1 Biomarker levels in control and congenital heart disease groups.

\begin{tabular}{llcccc}
\hline & \multicolumn{4}{c}{ Median (P25-75) } \\
\cline { 2 - 5 } & $n$ & Control group & $n$ & CHD group \\
\hline Troponin $(\mathrm{ng} / \mathrm{mL})$ & 19 & $0.01(0.01-0.02)$ & 33 & $0.01(0.01-0.04)$ \\
Myoglobin $(\mathrm{ng} / \mathrm{mL})$ & 20 & $50.95(34.38-73.65)$ & 26 & $58.30(33.88-80.55)$ & 0.710 \\
CK-MB $(\mathrm{ng} / \mathrm{mL})$ & 19 & $3.60(2.70-6.20)$ & 26 & $4.60(3.08-7.60)$ & 0.748 \\
\hline
\end{tabular}

$\mathrm{CHD}=$ congenital heart disease; $\mathrm{CK}-\mathrm{MB}=$ creatine kinase-MB mass. 
Table 2 Cardiac injury biomarkers in each group of congenital heart defect.

\begin{tabular}{lllll}
\hline & \multicolumn{3}{c}{ Median } \\
\cline { 2 - 5 } & $n$ & $\begin{array}{l}\text { Troponin } \\
(\mathrm{ng} / \mathrm{mL})\end{array}$ & $\begin{array}{l}\text { Myoglobin } \\
(\mathrm{ng} / \mathrm{mL})\end{array}$ & $\begin{array}{l}\text { CK-MB } \\
(\mathrm{ng} / \mathrm{mL})\end{array}$ \\
\hline RVPO & 6 & 0.01 & 55.90 & 4.90 \\
LVPO & 5 & 0.01 & 55.80 & 4.20 \\
Ebstein & 2 & 0.02 & 94.30 & 8.90 \\
TGA & 4 & 0.01 & 47.20 & 7.40 \\
L-R shunt & 6 & 0.01 & 60.15 & 2.75 \\
TAPVR & 1 & 0.01 & - & - \\
\hline
\end{tabular}

$C K-M B=$ creatine kinase-MB mass; Ebstein = Ebstein disease; $\mathrm{L}-\mathrm{R}$ shunt $=$ left-to-right shunts; $\mathrm{LVPO}=$ left ventricle pressure overload; RVPO = right ventricle pressure overload; TAPVR = total pulmonary anomalous venous return; $\mathrm{TGA}=$ transposition of great arteries.

Table 3 Demographics of patient's characteristics-surgical versus conservative treatment groups.

\begin{tabular}{|c|c|c|c|}
\hline & $\begin{array}{l}\text { Surgical group } \\
(n=10)\end{array}$ & $\begin{array}{l}\text { Conservative } \\
\text { treatment } \\
\text { group } \\
(n=14)\end{array}$ & $p$ \\
\hline $\begin{array}{l}\text { Gender } \\
\quad \text { (female/male) }\end{array}$ & $3 / 7$ & $4 / 10$ & $>0.999$ \\
\hline $\begin{array}{l}\text { Gestational age } \\
\text { (wk) }\end{array}$ & $37(37-40)$ & $38(38-39)$ & 0.745 \\
\hline Birth weight (g) & $\begin{array}{l}3145 \\
(2555-3660)\end{array}$ & $\begin{array}{l}3165 \\
(2874-3330)\end{array}$ & 0.770 \\
\hline \multicolumn{4}{|l|}{ Apgar score } \\
\hline $1 \mathrm{~min}$ & $9(8-9)$ & $9(8-9)$ & 0.296 \\
\hline $5 \min$ & $10(8-9)$ & $9(9-10)$ & 0.698 \\
\hline \multicolumn{4}{|c|}{ Types of congenital heart defects } \\
\hline RVPO & 2 & 4 & \\
\hline LVPO & 4 & 1 & \\
\hline Ebstein & 1 & 1 & \\
\hline TGA & 3 & 1 & \\
\hline$L-R$ shunt & 0 & 6 & \\
\hline TAPVR & 0 & 1 & \\
\hline
\end{tabular}

period [7.35 $(4.90-13.40) \mathrm{ng} / \mathrm{mL}]$ than in patients who were discharged home without surgery [4.2 (2.60-5.90) ng/ $\mathrm{mL}, p=0.032]$. Troponin I and myoglobin levels were not significantly different between conservative treatment and surgical groups (Table 4).

Receiver operator characteristic curves were generated, which plot a test's true positives against its false positives, for CK-MB, troponin I, and myoglobin (Figure 1). CK-MB exceeded our prespecified threshold of $\geq 75 \%$ area contained by the receiver operator characteristic curve. The area under the curve for the plot of CK-MB against surgery was $79.5 \%$. Test characteristics for various plasma levels of CK-MB as markers for surgery were determined. A cutoff of $\geq 4.6 \mathrm{ng} / \mathrm{mL}$ showed sensitivity of $87.5 \%$ and specificity of $63.6 \%$. The proportion of newborns who underwent cardiac surgery was higher among those who had a CK-MB of $\geq$ $4.6 \mathrm{ng} / \mathrm{mL}(p=0.026)$. Those with higher levels of CK-MB $(\geq 4.6 \mathrm{ng} / \mathrm{mL}$ ) presented an increased likelihood of being submitted to surgery (odds ratio $=12.25$; confidence interval: $1.08-138.99)$.

\subsection{Correlation between plasma biomarkers and echocardiographic parameters}

There was a statistically significant negative correlation (Figure 2) between CK-MB levels and TDI of the mitral valve lateral annulus peak early/late diastolic velocity ratio (MV $\left.E^{\prime} / A ; \rho=-0.480, p=0.018\right)$. Images of measurement of myocardial diastolic function $E^{\prime}$ and $A^{\prime}$ waves are exemplified in Figure 3. There was no correlation between CK-MB and the other echocardiographic parameters that were evaluated. For the ventricular systolic function parameters that were evaluated, the median (P25-75) values were $79.0(69.2-87.0)$ for left ventricle ejection fraction, 0.046 (0.032-0.050) for mitral valve lateral annulus TDI slope, 7.66 (7.08-9.93) for tricuspid annular plane systolic excursion, and $0.06(0.05-0.07)$ for TDI tricuspid valve slope. In control participants, there was no statistically significant correlation between CK-MB and TDI measurements $(\rho=0.112, p=0.680)$. Myoglobin and troponin I did not correlate with echocardiographic parameters.

\section{Discussion}

Troponin I, myoglobin, and CK-MB were not significantly higher in newborns with CHD than in healthy newborns, suggesting that newborns with a prenatal diagnosis of CHD do not present with ischemia at birth. To date, this is the largest study to be published about cardiac injury

Table 4 Cardiac biomarkers by type of treatment (surgical vs. conservative).

\begin{tabular}{lccccc}
\hline & $n$ & $\begin{array}{c}\text { Surgical treatment } \\
\text { Median }(\text { P25-75) }\end{array}$ & $\begin{array}{c}\text { Conservative treatment } \\
\text { Median (P25-75) }\end{array}$ & $n$ & $p$ \\
\hline Troponin $(\mathrm{ng} / \mathrm{mL})$ & 9 & $0.01(0.01-0.03)$ & $0.01(0.01-0.02)$ & 0.505 \\
Myoglobin $(\mathrm{ng} / \mathrm{mL})$ & 8 & $64.90(49.35-119.93)$ & $55.00(32.00-64.30)$ & 14 & 11 \\
CK-MB $(\mathrm{ng} / \mathrm{mL})$ & 8 & $7.35(4.90-13.40)$ & $4.2(2.60-5.90)$ & 0.148 \\
\hline
\end{tabular}

${ }^{*} p<0.05$.

$\mathrm{CK}-\mathrm{MB}=$ creatine kinase-MB mass. 

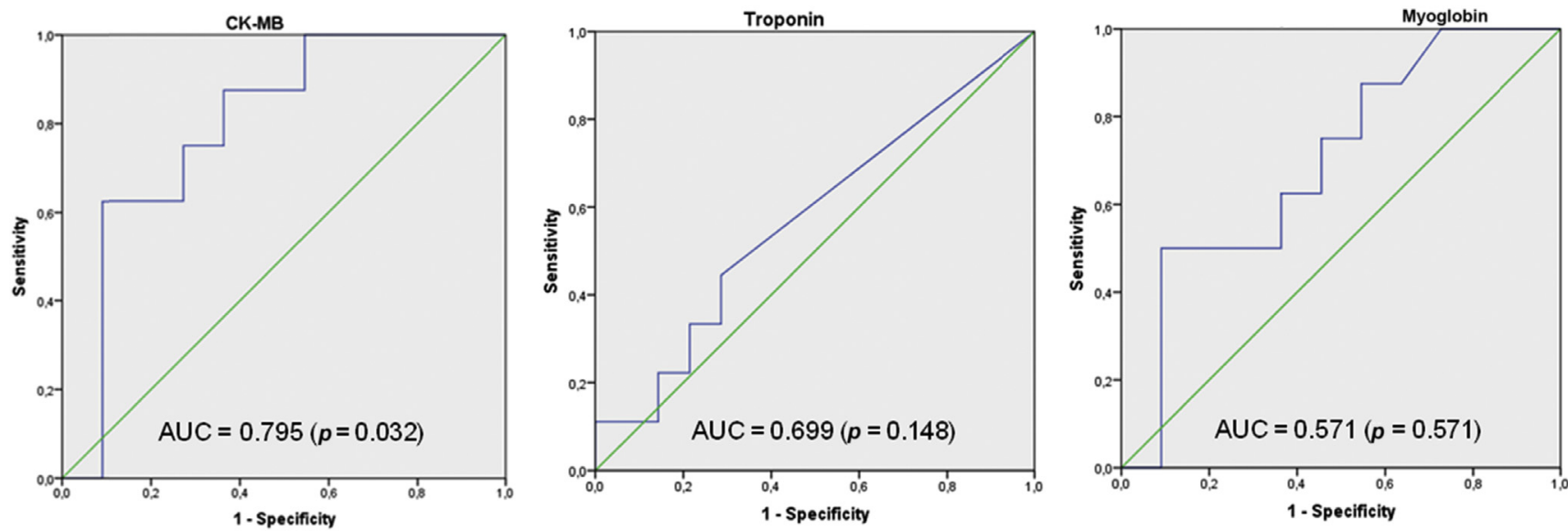

Figure 1 Receiver operator characteristic curves for CK-MB, troponin, and myoglobin. False positives (1-specificty) were plotted against true positives (sensitivity). A test for which the area under the curve (c-statistic) is $\geq 0.75$ was defined as a useful test. $\mathrm{AUC}=$ area under the curve; $\mathrm{CK}-\mathrm{MB}=$ creatine kinase $-\mathrm{MB}$ mass.

biomarkers' value in newborns with a broad spectrum of CHD before surgery. Kocylowski et $\mathrm{al}^{6}$ evaluated injury markers in postpartum cord blood in 10 newborns with CHD. Troponin T was increased only in two out of 10 newborns with CHD; in CK-MB and myoglobin there were no differences from normal. Liesemer et $\mathrm{al}^{24}$ reviewed the use of troponin in pediatric practice; however, in the newborn group (with a variety of diagnosis, including birth asphyxia, respiratory distress syndrome, meconium aspiration, or twin-twin transfusion), outcome analysis was not performed. Troponin has been studied in the postoperative setting with discrepant conclusions. Bottio et $\mathrm{al}^{25}$ evaluated

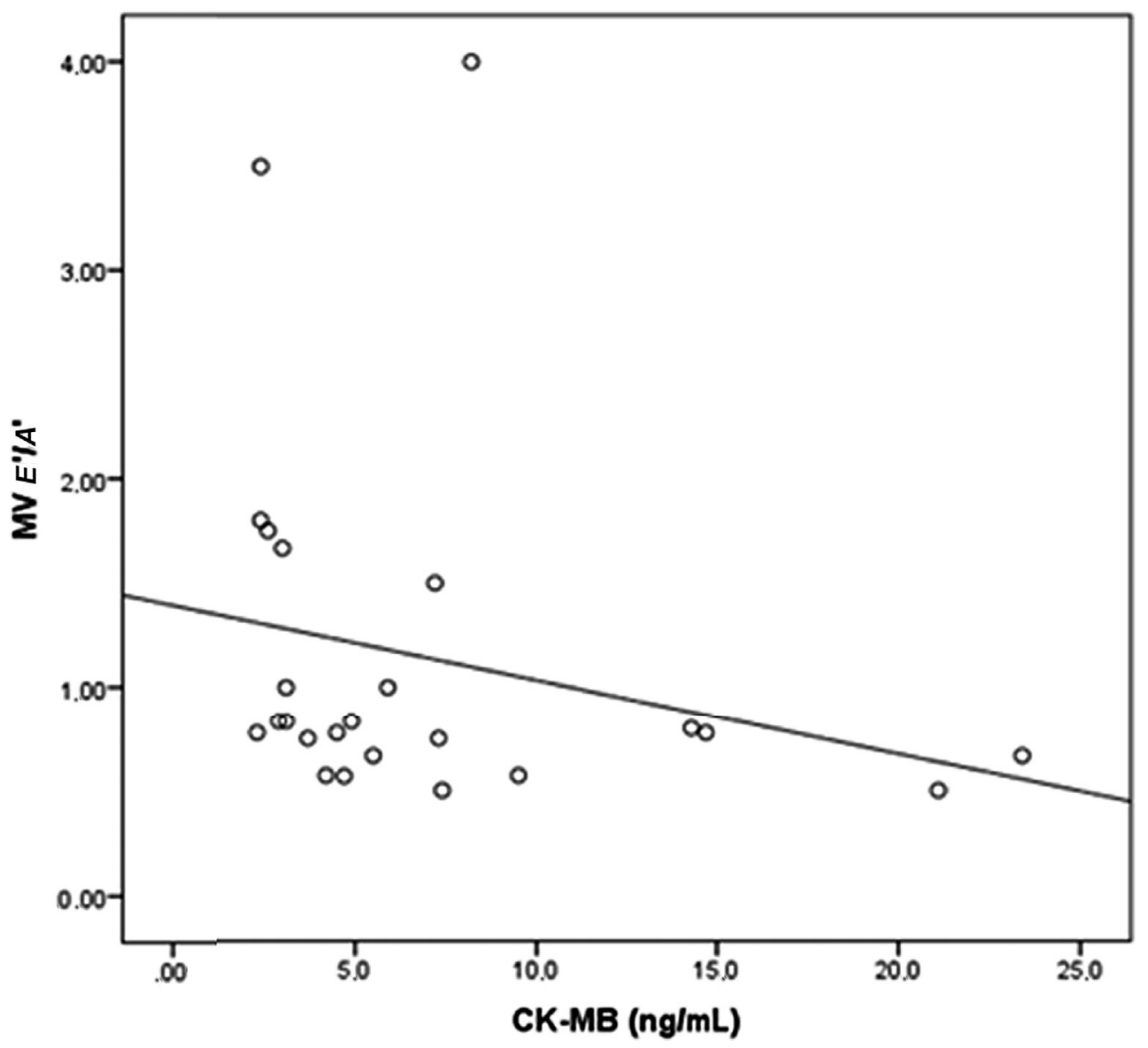

Figure 2 Correlation of mitral valve annulus $E^{\prime} / A^{\prime}\left(M V E^{\prime} / A^{\prime}\right)$ with CK-MB. Spearman correlation coefficient $=-0.480, p=0.018$. $\mathrm{CK}-\mathrm{MB}=$ creatine kinase-MB mass; $M V E^{\prime} / A^{\prime}=$ mitral valve lateral annulus peak early/late diastolic velocity ratio. 


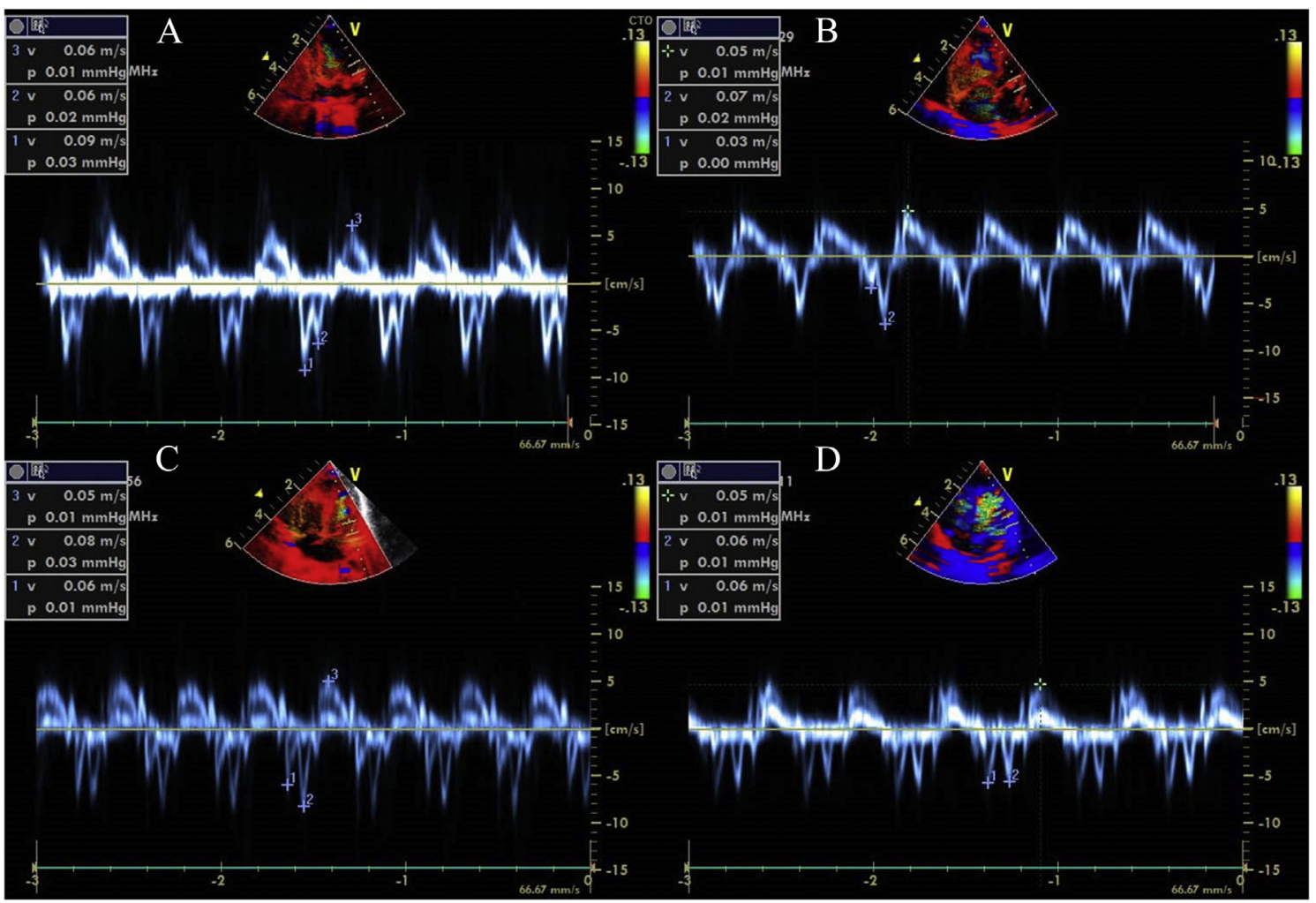

Figure 3 Tissue Doppler images of (A) myocardial diastolic function (mitral valve lateral annulus $E^{\prime} / A^{\prime}$ ) from a healthy newborn, (B) an aortic atresia patient with a ventricular septal defect, (C) transposition of the great arteries, and (D) a tetralogy of Fallot.

troponin in the postoperative period in newborns and children; they concluded that troponin I was a specific and sensitive marker of myocardial injury after cardiac surgery and that it might predict early-hospital outcomes, but it lost prognostic significance over the long term. Bojan et $\mathrm{al}^{26}$ suggested that routine monitoring of troponin I after surgery for CHD was not useful in patients younger than 1 year.

CK-MB was elevated in newborns after perinatal and neonatal hypoxia-ischemia, but this elevation was not specific enough to be of clinical value. ${ }^{7,11}$ Some conditions such as perinatal hypoxia-ischemia, type of delivery, Apgar score, and saturation of oxygen may influence cardiac biomarkers. However, no cases of asphyxia were observed in our study. Moreover, cardiac biomarkers did not differ according to the mode of delivery, Apgar score, or patient's saturation of oxygen.

To date, the present study is the only one to show a correlation between cardiac injury biomarkers and TDI in newborns with CHD. CK-MB was negatively correlated with $M V E^{\prime} / A^{\prime}$. This TDI parameter may be obtained in all CHD and allow us to evaluate the diastolic function of these newborns. Previously, TDI $E^{\prime} / A^{\prime}$ ratio of three ventricular walls was evaluated from fetus to neonate and was increased during the transition from fetal to neonatal circulation. ${ }^{27}$ TDI $E^{\prime} / A^{\prime}$ was previously used in newborns of diabetic mothers, and a significant decrease of the $E^{\prime} / A^{\prime}$ ratio at the tricuspid annulus was found in infants of mothers with pregestational diabetes compared with those with gestational diabetes. ${ }^{28} \mathrm{Kim}$ et $\mathrm{al}^{22}$ evaluated TDI $E^{\prime} / A^{\prime}$ parameter as a marker of diastolic function and correlated it with brain natriuretic peptide (BNP) levels in a population of liver transplant recipients. TDI has also been used in newborns for each myocardial segment, including peak early diastolic velocity $\left(E^{\prime}\right)$ and peak late diastolic velocity $\left(A^{\prime}\right)$, to evaluate postnatal left ventricular diastolic function after fetal aortic valvuloplasty. Mitral annular early diastolic tissue velocity $\left(E^{\prime}\right)$ was lower in patients with fetal aortic valvuloplasty and those with aortic stenosis than in controls in the neonatal period. ${ }^{21}$ Dubin et $\mathrm{al}^{29}$ studied the associations between TDI and NT-proBNP, and concluded that TDI imaging may be more useful than traditional measures of diastolic function in a population of end-stage renal disease.

In neonates with respiratory distress syndrome, there was a statistically significant negative correlation between cardiac troponin T on Day 1 and the fractional shortening measured on the same day; however, there was no statistically significant correlation between left ventricular output and cardiac troponin T across the 3 days. ${ }^{30}$ No correlations were found between troponin I and echocardiographic measurements in perinatal asphyxia. ${ }^{31}$ The diagnostic role of troponin $T$ has been studied in a group of newborns with CHD, and troponin T levels in newborns with heart pathology were higher than those in healthy ones. However, troponin T concentrations in patients with CHD were correlated neither with clinical symptoms of heart failure, nor with echocardiographic markers of left ventricular function. ${ }^{32}$ The absence of a correlation between cardiac output and cardiac biomarkers may be because of the presence of a PDA, which would lead to an increased left ventricular output without increasing systemic blood flow. $^{30,33}$ In the presence of a PDA, left ventricular output does not reflect the systemic blood flow. ${ }^{19}$ 
The limitations of the present study are the number of participants and the lack of biomarker monitoring over time and postsurgery. CK-MB and myoglobin were different depending on the blood source. The cord blood levels (collected immediately after birth) were lower than the peripheral venous blood levels (collected in the first few hours after birth). This may be explained by the circulatory transition from fetal to neonatal life. In healthy newborns, biomarker concentrations are highest during the first 4 days of life, possibly due to the stress of the birth process and due to adaptation of the neonate to postnatal circulation. ${ }^{34}$ In newborns with CHD, this transition process may have even more hemodynamic impact since the ductus closure, the decrease in pulmonary vascular resistance, and the increase in systemic vascular resistance may overload the heart, explaining the higher biomarker levels after birth. An understanding of fetal hemodynamics and the acute and chronic changes that occur with the transition from fetal to newborn circulation are important for the care of the healthy newborns and crucial to the recognition, diagnosis, and management of the newborn with significant CHD. ${ }^{35,36}$

In conclusion, CK-MB levels in the first hours of life are higher in newborns that need neonatal cardiac surgery and may be an indicator of myocardial diastolic function. TDI may be more useful than traditional measures of diastolic function in a population of newborns with CHD. Evaluation of cardiac biomarkers in umbilical cord blood is feasible and may be routinely used as part of the management of newborns with CHD.

\section{Conflicts of interest}

The authors have no conflicts of interest to disclose relevant to this article.

\section{Acknowledgments}

No external funding was secured for this study.

\section{References}

1. Mahajan VS, Jarolim P. How to interpret elevated cardiac troponin levels. Circulation 2011;124:2350-4.

2. Wu AH, Apple FS, Gibler WB, Jesse RL, Warshaw MM, Valdes Jr R. National Academy of Clinical Biochemistry Standards of Laboratory Practice: recommendations for the use of cardiac markers in coronary artery diseases. Clin Chem 1999; 45:1104-21.

3. Baum H, Hinze A, Bartels P, Neumeier D. Reference values for cardiac troponins $\mathrm{T}$ and $\mathrm{I}$ in healthy neonates. Clin Biochem 2004;37:1079-82.

4. Bader D, Kugelman A, Lanir A, Tamir A, Mula E, Riskin A. Cardiac troponin I serum concentrations in newborns: a study and review of the literature. Clin Chim Acta 2006;371:61-5.

5. Trevisanuto D, Pitton M, Altinier S, Zaninotto M, Plebani M, Zanardo V. Cardiac troponin I, cardiac troponin T and creatine kinase $M B$ concentrations in umbilical cord blood of healthy term neonates. Acta Paediatr 2003;92:1463-7.

6. Kocylowski RD, Dubiel M, Gudmundsson S, Sieg I, Fritzer E, Alkasi $\mathrm{O}$, et al. Biochemical tissue-specific injury markers of the heart and brain in postpartum cord blood. Am J Obstet Gynecol 2009;200:273.e1-273.e25.
7. Omokhodion SI, Losekoot TG, Jaiyesimi F. Serum creatine kinase and creatine kinase-MB isoenzyme activities in perinatally asphyxiated newborns. Eur Heart J 1991;12:980-4.

8. Mair J, Morandell D, Genser N, Lechleitner P, Dienstl F, Puschendorf B. Equivalent early sensitivities of myoglobin, creatine kinase MB mass, creatine kinase isoform ratios, and cardiac troponins I and T for acute myocardial infarction. Clin Chem 1995;41:1266-72.

9. Antman EM, Tanasijevic MJ, Thompson B, Schactman M, McCabe CH, Cannon CP, et al. Cardiac-specific troponin I levels to predict the risk of mortality in patients with acute coronary syndromes. New Engl J Med 1996;335:1342-9.

10. Trevisanuto D, Doglioni N, Altinier S, Zaninotto M, Plebani M, Zanardo V. Cardiac troponin I at birth is of fetal-neonatal origin. Arch Dis Child Fetal Neonatal Ed 2009;94:F464-6.

11. Türker G, Babaoğlu K, Gökalp AS, Sarper N, Zengin E, Arisoy AE. Cord blood cardiac troponin I as an early predictor of short-term outcome in perinatal hypoxia. Biol Neonate 2004;86:131-7.

12. Korraa A, Ezzat MH, Bastawy M, Aly H, El-Mazary AA. Abd ElAziz L. Cardiac troponin I levels and its relation to echocardiographic findings in infants of diabetic mothers. Ital J Pediatr 2012;38:39.

13. Sugimoto M, Ota K, Kajihama A, Nakau K, Manabe H, Kajino H. Volume overload and pressure overload due to left-to-right shunt-induced myocardial injury. Evaluation using a highly sensitive cardiac Troponin-I assay in children with congenital heart disease. Circ J 2011;75:2213-9.

14. Kogaki S. Highly sensitive cardiac troponin-I in congenital heart disease. Circ J 2011;75:2056-7.

15. Vijlbrief DC, Benders MJ, Kemperman H, van Bel F, de Vries WB. Use of cardiac biomarkers in neonatology. Pediatr Res 2012;72:337-43.

16. Gaze DC, Collinson PO. Cardiac troponin I should be interpreted with caution in paediatric neonatal patients. Concerning Turker et al. Cord blood cardiac troponin I as an early predictor of short-term outcome in perinatal hypoxia. Biol Neonate 2005;87:19.

17. Ficial B, Finnemore AE, Cox DJ, Broadhouse KM, Price AN, Durighel G, et al. Validation study of the accuracy of echocardiographic measurements of systemic blood flow volume in newborn infants. J Am Soc Echocardiogr 2013;26:1365-71.

18. Harada K, Shiota T, Takahashi Y, Tamura M, Toyono M, Takada G. Doppler echocardiographic evaluation of left ventricular output and left ventricular diastolic filling changes in the first day of life. Pediatr Res 1994;35:506-9.

19. Mertens L, Seri I, Marek J, Arlettaz R, Barker P, McNamara P, et al. Targeted neonatal echocardiography in the neonatal intensive care unit: practice guidelines and recommendations for training. Eur J Echocardiogr 2011;12:715-36.

20. Roberson DA, Cui W, Chen Z, Madronero LF, Cuneo BF. Annular and septal Doppler tissue imaging in children: normal z-score tables and effects of age, heart rate, and body surface area. $J$ Am Soc Echocardiogr 2007;20:1276-84.

21. Friedman KG, Margossian R, Graham DA, Harrild DM, Emani SM, Wilkins-Haug LE, et al. Postnatal left ventricular diastolic function after fetal aortic valvuloplasty. Am J Cardiol 2011;108:556-60.

22. Kim YK, Seong SH, Jun IG, Chin JH, Sang BH, Park YS, et al. Preoperative echocardiographic indices associated with elevated brain natriuretic peptide in liver transplant recipients. Transplant Proc 2011;43:1691-5.

23. Lowenthal A, Camacho BV, Lowenthal S, Natal-Hernandez L, Liszewski W, Hills NK, et al. Usefulness of B-type natriuretic peptide and $\mathrm{N}$-terminal pro-B-type natriuretic peptide as biomarkers for heart failure in young children with single ventricle congenital heart disease. Am J Cardiol 2012;109:866-72.

24. Liesemer K, Casper TC, Korgenski K, Menon SC. Use and misuse of serum troponin assays in pediatric practice. Am J Cardiol 2012;110:284-9. 
25. Bottio T, Vida V, Padalino M, Gerosa G, Stellin G. Early and long-term prognostic value of troponin-I after cardiac surgery in newborns and children. Eur J Cardiothorac Surg 2006;30: $250-5$.

26. Bojan M, Peperstraete H, Lilot M, Vicca S, Pouard P, Vouhé P. Early elevation of cardiac troponin I is predictive of short-term outcome in neonates and infants with coronary anomalies or reduced ventricular mass undergoing cardiac surgery. $J$ Thorac Cardiovasc Surg 2012;144:1436-44.

27. Iwashima S, Sekii K, Ishikawa T, Itou H. Serial change in myocardial tissue Doppler imaging from fetus to neonate. Early Hum Dev 2013;89:687-92.

28. Al-Biltagi M, Tolba OA, Rowisha MA, Mahfouz Ael S, Elewa MA. Speckle tracking and myocardial tissue imaging in infant of diabetic mother with gestational and pregestational diabetes. Pediatr Cardiol 2015;36:445-53.

29. Dubin RF, Beatty AL, Teerlink JR, Schiller NB, Alokozai D, Johansen KL. Associations of tissue Doppler imaging with NTproBNP and hs-TnT: a pilot study in end-stage renal disease. Echocardiography 2014;31:1205-12.

30. Clark SJ, Newland P, Yoxall CW, Subhedar NV. Sequential cardiac troponin $T$ following delivery and its relationship with myocardial performance in neonates with respiratory distress syndrome. Eur J Pediatr 2006;165:87-93.

31. Vijlbrief DC, Benders MJ, Kemperman H, van Bel F, de Vries WB. Cardiac biomarkers as indicators of hemodynamic adaptation during postasphyxial hypothermia treatment. Neonatology 2012;102:243-8.

32. Tarkowska A, Furmaga-Jabłońska W. The evaluation of diagnostic role of cardiac troponin T (cTnT) in newborns with heart defects. Scientific World Journal 2012;2012:682538.

33. Gessner I, Krovetz LJ, Benson RW, Prystowsky H, Stenger V, Eitzman DV. Hemodynamic adaptations in the newborn infant. Pediatrics 1965;36:752-62.

34. Clerico A, Recchia FA, Passino C, Emdin M. Cardiac endocrine function is an essential component of the homeostatic regulation network: physiological and clinical implications. Am J Physiol Heart Circ Physiol 2006;290:H17-29.

35. Friedman AH, Fahey JT. The transition from fetal to neonatal circulation: normal responses and implications for infants with heart disease. Semin Perinatol 1993;17:106-21.

36. Kiserud T, Acharya G. The fetal circulation. Prenat Diagn 2004; 24:1049-59. 